This article was downloaded by: [Deakin University]

On: 9 February 2011

Access details: Access Details: [subscription number 907464590]

Publisher Routledge

Informa Ltd Registered in England and Wales Registered Number: 1072954 Registered office: Mortimer House, 3741 Mortimer Street, London W1T 3JH, UK

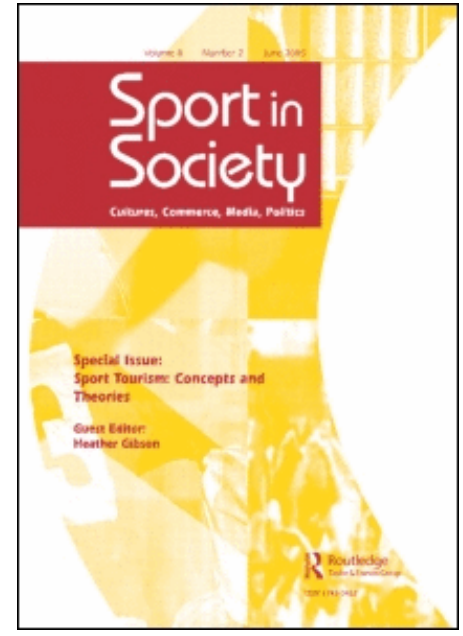

\title{
Sport in Society
}

Publication details, including instructions for authors and subscription information:

http://www.informaworld.com/smpp/title content=t713634841

\section{Social capital and sport events: spectator attitudinal change and the} Homeless World Cup

Emma Sherrya; Adam Karg ${ }^{\mathrm{b}}$; Fiona O'Mayc

${ }^{\mathrm{a}}$ Centre for Sport and Social Impact, LaTrobe University, Australia ${ }^{\mathrm{b}}$ School of Management and Marketing, Deakin University, Australia ${ }^{c}$ Faculty of Health and Social Science, Queen Margaret University, UK

Online publication date: 13 January 2011

To cite this Article Sherry, Emma, Karg, Adam and O'May, Fiona(2011) 'Social capital and sport events: spectator attitudinal change and the Homeless World Cup', Sport in Society, 14: 1, $111-125$

To link to this Article: DOI: 10.1080/17430437.2011.530015

URL: http://dx.doi.org/10.1080/17430437.2011.530015

\section{PLEASE SCROLL DOWN FOR ARTICLE}

Full terms and conditions of use: http://www.informaworld.com/terms-and-conditions-of-access.pdf

This article may be used for research, teaching and private study purposes. Any substantial or systematic reproduction, re-distribution, re-selling, loan or sub-licensing, systematic supply or distribution in any form to anyone is expressly forbidden.

The publisher does not give any warranty express or implied or make any representation that the contents will be complete or accurate or up to date. The accuracy of any instructions, formulae and drug doses should be independently verified with primary sources. The publisher shall not be liable for any loss, actions, claims, proceedings, demand or costs or damages whatsoever or howsoever caused arising directly or indirectly in connection with or arising out of the use of this material. 


\title{
Social capital and sport events: spectator attitudinal change and the Homeless World Cup
}

\author{
Emma Sherry ${ }^{\mathrm{a}}$, Adam Karg ${ }^{\mathrm{b}}$ and Fiona O’May ${ }^{\mathrm{c}}$ \\ ${ }^{a}$ Centre for Sport and Social Impact, LaTrobe University, Australia; ${ }^{b}$ School of Management and \\ Marketing, Deakin University, Australia; ${ }^{c}$ Faculty of Health and Social Science, Queen Margaret \\ University, UK
}

\begin{abstract}
Increasingly, the staging of sport events promoting a social cause has become commonplace. This study collects data from spectators at two consecutive Homeless World Cups (Melbourne 2008 and Milan 2009) - an event that seeks to raise awareness of the global issue of homelessness. This paper aims to advance the understanding of specific attitude changes in spectators and to identify how these can be activated towards behaviours to produce enduring social impacts for events. The role of social capital in attitudinal change is emphasized, specifically bridging capital that signifies the creation of relationships between disparate individuals. Quantitative analysis provides insight into spectator demographics and attendance patterns, and contributes to the understanding of spectator attitudes towards homelessness. Patterns and trends suggest demographic and attendance variables align with differing forms of attitudinal change, and further suggest a hierarchy of effects may be relevant to the findings and provide a valuable contribution to future research.
\end{abstract}

\section{Introduction}

The use of sport in pursuit of social capital is increasing in popularity, as illustrated by the significant number of sporting events promoting a social cause. This article explores the role of spectators within the framework of such sport events and specifically focuses on the role of spectators in facilitating the delivery of social capital. The impact of hosting an event can be determined across multiple strata, including economic, environmental and social, with the majority of research focusing on the economic impact of events. Current research is extending the investigation to explain non-economic benefits that may be ascribed to the hosting of an event within a community. This is encouraged by Chalip's identification of the potential for increased research addressing the social value of sport events. ${ }^{1}$

The Homeless World Cup (HWC) is an international, annual street soccer competition with multiple aims: firstly to promote social opportunities, including access to support services and increased social interaction, for participants experiencing homelessness and associated social disadvantage; and additionally to raise awareness of the issues of homelessness on a societal level. Each HWC team is selected by their nation through participation in grass-roots street soccer programmes. To be eligible to participate in the HWC, a player has to have been homeless or in a substance-abuse programme within the last two years, with both men and women eligible to represent their country. The definition of homelessness varies between developed and developing nations, with the understanding of homelessness in a country such as Australia divergent from that of Liberia. However

\footnotetext{
*Email: e.sherry@1atrobe.edu.au
} 
each participant faces the challenge of homelessness and marginalization within the context of their own community.

A significant increase in international participation from 18 to 56 countries since its inception in 2003 has established the HWC as a major sporting event, complete with highprofile media coverage. ${ }^{2}$ However, the HWC remains a unique event as the participants originate from marginalized backgrounds, rather than elite or mainstream sporting origins. The HWC was hosted in Melbourne, Australia in 2008 and in Milan, Italy in 2009. During each event a survey of spectators was undertaken to attempt to measure the views of the spectators towards the issue of homelessness. Of particular focus was whether attendance at this event had altered their perceptions of homelessness.

\section{Social capital}

As an event with a social cause as its primary purpose, the HWC pursues the goal of the achievement of a variety of social outcomes, including increased awareness of the issue of homelessness. Social capital 'comes about through changes in the relations among persons that facilitate action'. ${ }^{3}$ This understanding of social capital is applicable within an event such as the HWC where sport is provided as a modality for the delivery of social capital to participants. The event additionally provides the opportunity for one group (the broader community) to see another disadvantaged or marginalized group (the HWC athletes in particular, but the homeless more broadly) in another, more positive light.

Coleman's interpretation of social capital, in which he refers to both bonding capital and bridging capital, has become popular within contemporary policy-oriented discourses about sport and leisure. ${ }^{4}$ Bonding capital is observed in player-to-player interactions where relationships between people who are similar are formed (in this case, between the players). However it is the concept of bridging that is pertinent to this article, as it refers to the relationships developed with people that are different from oneself (i.e. between players and spectators, albeit a conceptual rather than implicit relationship). Social capital, according to Jarvie, has attracted a great deal of attention as it is seen as a way of contributing to social inclusion for marginalized groups. ${ }^{5}$ This paper adopts a social capital theory: it assumes that participation in an activity that involves similar levels of participation from other individuals, and which has stated aims and outcomes, leads to the accrual of social capital for the participants. According to Smith and Westerbeek, sport provides an effective anchor for individuals and a fertile environment for the development of relationships within communities that leads to an increase in social capital. ${ }^{6}$ The contribution of sport to social capital is viewed as of equal importance and personal significance as other measurable outcomes, such as health benefits.

Research on the social and community benefits of events has recently focused on the concept of leveraging to achieve these benefits. ${ }^{7}$ The HWC uses the power and popularity of sport, specifically soccer, as leverage to increase awareness of the issue of homelessness, and also poverty. Misener and Mason explore the link between sport events and the development of community networks, where sport potentially provides an opportunity for the development of social networks. ${ }^{8}$ Sport events may also facilitate a renewed sense of community for those involved. ${ }^{9}$

Chalip explains that the sense of community engendered through sport events fosters social capital, as sport events assist in facilitating relationships where previously this may have not been possible. ${ }^{10}$ The goal of the Homeless World Cup Organisation (the event governing body) is to use the HWC, in its capacity as a world-class event, to attract media interest in an effort to maximize funding opportunities and thus the promotion of local 
'grass-roots' concepts. ${ }^{11}$ This stated aim would benefit from the acquisition of social capital between spectator and player, in addition to that displayed between players. The sport event, in this case the HWC, has been developed specifically to draw attention to the social issue of homelessness to communities and individuals (as spectators) who may not otherwise demonstrate any interest. This facilitates the delivery of a twofold agenda by acquiring support from spectators through the development of social capital (through attitudinal change), and secondly to facilitate ongoing opportunities that develop social capital for marginalized individuals at a grass-roots level.

Authors have noted that a sense of community pride and well being are indicators of social capital, ${ }^{12}$ and therefore the concept of social capital has relevance in the investigation of the social impacts of events. It is argued that sport can act as a relevant and effective intermediary in the development of social capital, given the multifaceted ability of sport to contribute to health, engage a diverse audience and promote social inclusion.

The impact of participation in sport events on marginalized or socially excluded groups has been an area of recent research focus. Collins states that participating in a sport event 'requires some confidence, some skills, some knowledge, an ability to manage time and relationships, and having a group of supportive friends and companions, including some who share the same desire to take part' in the activity, thus identifying social bonding as a benefit of sport participation. ${ }^{13}$ In a review of literature undertaken by Long and Sanderson, the most commonly claimed community benefits for sport-event participation include enhanced confidence and self-esteem; empowering disadvantaged groups; encouraging pride in the community; and improving health. ${ }^{14}$ Although there is a lack of substantiated research on the social outcomes and benefits of sport participation, ${ }^{15}$ authors suggest that sport participation for socially excluded groups may have a substantial positive consequence for the individual, as well as making a valuable contribution to communities. ${ }^{16}$

This paper postulates that an increase in positive perception by spectators can be realized as an increase in social capital, as attitudinal change is conceived to be facilitating bridging capital between these groups (directly or indirectly). Green states that although it may be impossible to prove the link between sport and social change, it is possible to examine different programmes, those successful and not, and begin to identify the common features or conditions of the successful programs. ${ }^{17}$ The HWC provides an excellent exploratory case study of the ability of a sport event to create attitudinal change that delivers social benefits, and therefore engenders social capital, for both the participants and spectators.

\section{Methodology}

\section{Participants}

Data in this study were collected from a random intercept sample of spectators during two consecutive annual HWC events held in Melbourne in December 2008 and Milan in September 2009.This research was initially undertaken as an exploratory study for the Melbourne 2008 HWC and, after a review of the preliminary results, the researchers, in collaboration with the HWC, repeated the research in the subsequent year during the Milan 2008 HWC.

The questionnaire investigated demographic information and individual attendance at the event. It also contained items concerning attitudes towards the benefits of the event and individual attitudes towards the social issue of homelessness. Finally, an exploratory section enquired whether attitudes had changed as a result of attending the HWC and included an open-ended response question to identify how attitude changes had occurred. 
Surveys were administered at the event by a group of volunteers. Overall, 366 completed surveys from the Melbourne event and 145 responses from the Milan were gathered across the seven days of competition in each city, for a total sample size of 511.

The following section provides a detailed comparison of demographic data of the spectators at both the Melbourne 2008 HWC and the Milan 2009 HWC. Attendance and demographic characteristics for both events are shown in Table 1.

It can be clearly noted from Table 1 that, although the two events were hosted by different nations and host cities, the demographics and attendance patterns of the spectators attending the HWC events are very similar. Although each city would appear to be socially and economically quite different, both locations are large, first-world capital cities with strong business, arts and sport communities.

The different types of locations and times of year of the hosting of each event may explain the larger sample size of the Melbourne data. It must be noted that the event was

Table 1. Demographic and attendance characteristics of data samples

\begin{tabular}{|c|c|c|c|c|c|}
\hline \multirow[b]{2}{*}{ City } & & & \multicolumn{2}{|l|}{ Sample 1} & \multirow{2}{*}{ Sample 2} \\
\hline & & & Melbourne & & \\
\hline Year of collection & & & 2008 & & 2009 \\
\hline Respondents & & & $\mathrm{n}=366$ & & $\mathrm{n}=145$ \\
\hline \multirow[t]{3}{*}{ Gender } & & $\mathrm{n}$ & $\%$ & $\mathrm{n}$ & $\%$ \\
\hline & Male & 157 & $42.9 \%$ & 56 & $38.6 \%$ \\
\hline & Female & 209 & $57.1 \%$ & 89 & $61.4 \%$ \\
\hline \multicolumn{6}{|l|}{ Age } \\
\hline & $18-25$ years & 127 & $34.7 \%$ & 37 & $25.5 \%$ \\
\hline & $25-29$ years & 74 & $20.2 \%$ & 20 & $13.8 \%$ \\
\hline & $30-34$ years & 52 & $14.2 \%$ & 21 & $14.5 \%$ \\
\hline & $35-50$ years & 69 & $18.9 \%$ & 46 & $31.7 \%$ \\
\hline & $50+$ years & 44 & $12.0 \%$ & 21 & $14.5 \%$ \\
\hline \multicolumn{6}{|l|}{ Origin of participant } \\
\hline & Host city & 257 & $70.2 \%$ & 76 & $52.4 \%$ \\
\hline & Elsewhere in host country & 24 & $6.6 \%$ & 17 & $11.7 \%$ \\
\hline & Overseas/outside host country & 85 & $23.2 \%$ & 52 & $35.9 \%$ \\
\hline \multicolumn{6}{|c|}{ Intention to attend the event } \\
\hline & Passing through the area & 135 & $36.9 \%$ & 70 & $48.3 \%$ \\
\hline & Intentionally attending the event & 231 & $63.1 \%$ & 75 & $51.7 \%$ \\
\hline \multicolumn{6}{|c|}{ Primary Interest in event* } \\
\hline & Soccer & 196 & $53.6 \%$ & 74 & $51.0 \%$ \\
\hline & Community event & 172 & $47.0 \%$ & 83 & $57.2 \%$ \\
\hline & Concept of the HWC & 244 & $66.7 \%$ & 95 & $65.5 \%$ \\
\hline \multicolumn{6}{|l|}{ Attendance (days) } \\
\hline & One & 229 & $62.6 \%$ & 78 & $53.8 \%$ \\
\hline & Two & 74 & $20.2 \%$ & 45 & $31.0 \%$ \\
\hline & Three & 32 & $8.7 \%$ & 11 & $7.6 \%$ \\
\hline & Four or more days & 31 & $8.5 \%$ & 11 & $7.6 \%$ \\
\hline \multicolumn{6}{|c|}{ Attendance (average hours per visit) } \\
\hline & One & 125 & $34.2 \%$ & 44 & $30.3 \%$ \\
\hline & Two to three & 175 & $47.8 \%$ & 65 & $44.8 \%$ \\
\hline & Four to five & 38 & $10.4 \%$ & 25 & $17.2 \%$ \\
\hline & More than five & 28 & $7.7 \%$ & 11 & $7.6 \%$ \\
\hline
\end{tabular}

*Multiple responses accepted for this option therefore percentages do not equal 100 
held at different times of the year in each city - during the peak Christmas shopping period and warm summer weather of Melbourne in December, and during autumn, in September, in Milan. Both cities hosted the event in prominent public locations to intentionally attract the attention of passers-by, although the Milan location was less central than the Federation Square location in Melbourne. This may also account for a greater proportion of Melbourne spectators intentionally attending the event (63.1\%) as compared to Milan (51.7\%). The greater proportion of spectators from Milan originating from overseas (35.9\%) compared to Melbourne (23.2\%) could best be explained by the geography of Italy compared to Australia. The vast landscape and isolation of Australia may equate to a lower proportion of international and interstate visitors, as compared to Italy, where international travel is more geographically and financially accessible. A denser population and smaller landmass may also contribute towards the findings of a higher contingent of Italian visitors from outside Milan (11.7\%) as opposed to Melbourne $(6.6 \%)$. Both cities recorded slightly higher female than male attendance. Melbourne recorded a higher number of attendees from the 18-25 age bracket (34.7\% compared to $25.5 \%$ in Milan), whereas the highest contingent for Milan was the 35-50 age bracket (31.7\% attendance). Both samples recorded higher numbers of people intentionally attending the event than casual attendees. The spectator sample also revealed similar reasons for the majority of people attending, which was support of the concept of the HWC, as opposed to the staging of a community or sporting event. This demonstrates that the majority of spectators (66.7\% in Melbourne and 65.5\% in Milan) had an underlying interest in the concept of the HWC. Yet there also existed a large contingent of passers-by (Melbourne 26.9\% and Milan 48.3\%) that became spectators and were without preconceived notions, or any underlying interest in the issue of homelessness.

\section{Design and measurement}

The questionnaire was organized in five sections. The first section enquired about demographic information while the second contained questions relating to individual attendance at the event; particularly how many days and hours each respondent had attended the event, with whom they had attended and their major motivation for attending. The third section specifically enquired about the attitudes towards homelessness and whether they had changed as a result of the event. If the response was affirmative, an openended question asked the individual to specify the changes to their attitudes that had taken place. The final two sections contained items concerning attitudes towards the community benefits of the event and finally the individual's attitude towards the social issue of homelessness.

While large scales conceptualizing a range of impacts that events have on communities have progressed in literature, we sought here to work with items relating to positive community benefits as opposed to wider scales incorporating environmental, economic and forms of negative community impact on events. The community benefits items were therefore adapted from previous studies ${ }^{18}$ and were measured on response scales of 1 to 7 , anchored by 'Strongly Agree' and 'Strongly Disagree'. Initially, normality testing of both sets of data was undertaken which revealed no concerns. Eight items collected relating to 'Community Benefits' from Delamere, Wankel and Hinch ${ }^{19}$ were then subjected to Exploratory Factor Analysis (EFA) in line with the processes recommended by Fabrigar, Wegener, MacCallum and Strahan. ${ }^{20}$ The resultant analysis is presented for the earlier Melbourne sample but provided comparable results in the case of the Milan sample the following year at both EFA and Confirmatory Factor Analysis (CFA) stages. The data 
presented as suitable for EFA using the Kaiser-Meyer-Olkin Measure of Sampling Adequacy $(.887)$ and Bartlett's Test of Spherity $(\mathrm{p}<.001)$ and in line with Delamere, Wankel and Hinch ${ }^{21}$ six items loaded strongly as a single construct with items and their loadings shown in Appendix 1. Others that loaded weakly were removed from the analysis. The six remaining items showed an AVE of 0.58 and an Alpha of 0.89, suggesting the measures were valid and reliable representations of the intended construct. Further, a CFA structure in AMOS showed acceptable fit between the single structure and the data $(\mathrm{x}=90, \mathrm{df}=9, \mathrm{CFI}=0.94$, RMSEA $=0.074)$. Given this, a composite scale by which attitudes to community benefits could be assessed was generated using a mean score for the relevant items.

Given no established measures of attitudes towards homelessness or specific social issues existed, new items were formulated. These items were developed using sport and social inclusion research literature ${ }^{22}$ and drew on prior studies undertaken by the researcher with the Australian Community Street Soccer and HWC programmes. These scale items were designed to measure perceptions of individual concern about homelessness in distinct areas. We sought to test the attitudes of attendees to various statements regarding homelessness that were linked to awareness and importance of the issue. Five statements were developed with all responses collected on a scale of 1 to 7 , anchored by 'Strongly Agree' and 'Strongly Disagree' (see Table 2). This, combined with further exploratory analysis of the attitude changes, was expected to provide insight into the dimensions of social issues that underwent attitudinal change during the event.

\section{Data analysis}

Quantitative data analysis was undertaken using SPSS (v.16) using descriptive statistics, correlation analysis and independent $t$-tests to compare samples and groups. The thematic coding of open responses regarding attitudinal change towards the issue of homelessness was undertaken in line with established coding frameworks. ${ }^{23}$ The three attitudinal categories that resulted were developed through a process of open coding of all openended responses, followed by categorization into codes representing similar constructs. Two researchers were involved in the data collection at each site (one in Melbourne 2008 and one in Milan 2009), with the third researcher undertaking the quantitative analysis of the collected data as outlined above.

Table 2. Comparison of community benefits attitudinal score and homelessness items

\begin{tabular}{|c|c|c|c|}
\hline Community benefits (scaled) & Melbourne & Milan & $\mathrm{p}$ \\
\hline Scaled score (see method for description) & 5.36 & 5.30 & n.s \\
\hline Homelessness items & Melbourne & Milan & $\mathrm{p}$ \\
\hline $\begin{array}{l}\mathrm{H} 1 \text { - The issue of homelessness is } \\
\text { something I worry about }\end{array}$ & 5.63 & 5.80 & n.s \\
\hline $\begin{array}{l}\mathrm{H} 2 \text { - I feel that I can help make a positive } \\
\text { change to homelessness in (host country) }\end{array}$ & 4.68 & 4.39 & n.s \\
\hline $\begin{array}{l}\mathrm{H} 3 \text { - There are too many homeless people in } \\
\text { (host country) }\end{array}$ & 5.70 & 5.40 & n.s \\
\hline $\begin{array}{l}\text { H4 - I support the government's focus on } \\
\text { the homeless issue }\end{array}$ & 5.17 & 4.93 & n.s \\
\hline $\begin{array}{l}\text { H5 - There should be no homelessness in } \\
\text { a country like (host country) }\end{array}$ & 5.99 & 6.09 & n.s \\
\hline
\end{tabular}




\section{Results (quantitative data)}

\section{Comparison of events - Melbourne 2008 and Milan 2009}

Table 2 shows a comparison of the community benefits attitudinal score and comparison of the items used to assess attitudes towards homelessness. When reviewing Table 2, an independent samples $t$-test defines no significant difference between the two events (Melbourne and Milan) in terms of community benefits or any of the individual homelessness attitudes.

Further analysis shows that community benefits correlate significantly with each of the five homelessness items tested, indicating that a relationship exists between each of the items. The correlation matrix for the items is shown in Appendix 2.

\section{Impact of demographics and attendance on community benefits and homelessness items}

The impact of demographic and attendance factors was then analysed, including a focus on the perceptions of community events and homelessness attitudes. Table 3 shows that females and those from the host country were significantly higher on each measure, while no significant differences were found for age. Higher attendance (measured in total hours spent at the event) also resulted in significantly higher mean scores for community benefits and three of the five homelessness items.

Results presented in Table 3 reveal that spectator attendance patterns are evident, with origin and gender impacting significantly on the measures of community benefits and homelessness attitudes amongst the HWC spectators. However, perceptions of community benefit and attitudes towards homelessness did not differ significantly across age groups.

Table 3. Means comparison across demographic and attendance characteristics

\begin{tabular}{lllllll}
\hline & Community benefits & $\mathrm{H} 1$ & $\mathrm{H} 2$ & $\mathrm{H} 3$ & $\mathrm{H} 4$ & $\mathrm{H} 5$ \\
\hline Gender & & & & & & \\
Female & 5.59 & 5.91 & 4.83 & 5.99 & 5.33 & 6.13 \\
Male & 5.21 & 5.42 & 4.60 & 5.52 & 5.03 & 5.88 \\
$\mathrm{p}$ & 0.002 & 0.000 & 0.042 & 0.003 & $\mathrm{n} . \mathrm{s}$ & 0.014 \\
Origin & & & & & & \\
Host city & 5.47 & 5.77 & 4.91 & 6.00 & 5.19 & 6.12 \\
Interstate/regional & 5.55 & 5.74 & 4.95 & 5.77 & 5.31 & 6.00 \\
Overseas & 5.08 & 5.16 & 3.96 & 4.94 & 5.05 & 5.63 \\
p & 0.024 & 0.001 & 0.000 & 0.000 & n.s & 0.017 \\
Age & & & & & & \\
18-25 years & 5.17 & 5.52 & 4.64 & 5.62 & 5.00 & 5.83 \\
25-29 years & 5.31 & 5.39 & 4.61 & 5.69 & 5.16 & 5.91 \\
30-34 years & 5.55 & 5.91 & 5.04 & 5.50 & 5.20 & 6.06 \\
35-50 years & 5.47 & 5.81 & 4.59 & 5.96 & 5.18 & 6.17 \\
50+ years & 5.76 & 5.69 & 4.70 & 6.09 & 5.56 & 6.29 \\
p & 0.040 & $n . s$ & $n . s$ & $n . s$ & n.s & n.s \\
Attendance & & & & & & \\
Low & 5.11 & 5.37 & 4.42 & 5.48 & 5.01 & 5.83 \\
Medium & 5.28 & 5.72 & 4.58 & 5.70 & 5.14 & 5.93 \\
High & 5.57 & 5.75 & 5.03 & 5.78 & 5.24 & 6.15 \\
p & 0.004 & 0.027 & 0.003 & n.s. & n.s & 0.024 \\
\hline
\end{tabular}

N.B. Combined samples used given no significant differences were found between samples (Table 2). n.s. - not significant $(\mathrm{p}>.05)$ 
The item H4 does not reveal any significant difference as this refers to attitudes towards government policy rather than specific attitudes towards the issue of homelessness.

Female HWC spectators reported higher perceptions of community benefits and attitudes towards homelessness than the male spectators, and similarly, local and regional spectators also reported higher results than those spectators from overseas. These findings also demonstrate that more frequent spectator attendance (both in terms of days attended and hours attended each day), resulted in higher perceptions of community benefit for the HWC.

\section{Results (open-ended responses)}

The next stage of the research sought to understand the specific types of attitude change attendees had undergone, in order to better understand change towards attitudes linked to social causes. Spectators at the HWC in both Melbourne and Milan were asked 'Has this event changed your attitudes towards homelessness and homeless people?'. Those who had noted changed attitudes were asked an open-ended question seeking to explore the nature of the attitude change in relation to spectator perceptions of homelessness, and were provided with an opportunity to comment on any change in attitude towards the issue. One-hundred-and-eighty-five respondents across the two events contributed responses, which were subsequently thematically coded. The coding of the open responses categorized these changes in three areas: awareness, enhanced opinion and empathy. 'Awareness' indicated an increased general awareness of the issue of homelessness, 'enhanced opinion' responses were coded when the respondent indicated a positive change in attitude towards the homeless individuals, and 'empathy' indicated a response that reflected an understanding of the participants' personal situation and expressed empathy towards their experience. Examples of responses to the open-ended question for the three identified attitudinal changes of awareness, enhanced opinion and empathy are provided in Table 4.

Further, it was intended to gain insight into demographic or attendance patterns which might influence attitude change. Analysis of self-reported attitude change is shown in Tables 5 and 6. Overall, 52.2\% (Melbourne) and 54.5\% (Milan) of respondents indicated their attitudes towards the social event had changed as a result of event attendance.

Cross-group analysis of the levels of attitude change towards homelessness for both events (Table 6) demonstrated elevated levels of attitude change for higher attendance (both in terms of days attended and hours attended per day). Slightly more females

Table 4. Examples of Coded Attitude Changes

\begin{tabular}{|c|c|}
\hline Attitude change & Examples of open responses \\
\hline \multirow[t]{3}{*}{ Awareness } & "[I am] just more aware of the problem" \\
\hline & $\begin{array}{l}\text { "[I have gained an] understanding of the different types of homelessness and } \\
\text { understanding of how people became homeless" }\end{array}$ \\
\hline & "It [homelessness] is a bigger issue than I realized on a daily basis" \\
\hline \multirow{3}{*}{ Enhanced opinion } & "I see them as more capable than I used to" \\
\hline & "They are far more positive and motivated than I realized" \\
\hline & $\begin{array}{l}\text { "I discovered the desire of homeless people to change their own conditions, } \\
\text { and to be open to possibility" }\end{array}$ \\
\hline \multirow[t]{3}{*}{ Empathy } & "I now see homeless people are just like you and me, just less fortunate" \\
\hline & "Homeless [people are] not always to blame for their situation" \\
\hline & "They are just people, who had worse luck than the rest of us." \\
\hline
\end{tabular}


Table 5. The impact of events to change attitudes

\begin{tabular}{|c|c|c|c|c|}
\hline & & Sample 1 & & Sample 2 \\
\hline City & & Melbourne & & Milan \\
\hline Year of collection & & 2008 & & 2009 \\
\hline Respondents & & $\mathrm{n}=366$ & & $\mathrm{n}=145$ \\
\hline Affected attitudes to event themes & $\mathrm{n}$ & $\%$ & $\mathrm{n}$ & $\%$ \\
\hline \multicolumn{5}{|c|}{ Has this event changed your attitudes towards homelessness and homeless people? } \\
\hline Yes & 191 & $52.2 \%$ & 79 & $54.5 \%$ \\
\hline No & 175 & $47.8 \%$ & 66 & $45.5 \%$ \\
\hline \multicolumn{5}{|l|}{ Nature of attitude change } \\
\hline Awareness & 67 & $35.1 \%$ & 18 & $22.8 \%$ \\
\hline Enhanced opinion & 86 & $45.0 \%$ & 33 & $41.8 \%$ \\
\hline Empathy & 38 & $19.9 \%$ & 28 & $35.4 \%$ \\
\hline
\end{tabular}

changed their attitude towards the social issue and an enhanced opinion change was shown to be the most common type of attitude change for both samples. Intentional attendance also led to higher rates of attitude changes. However a difference was observed in the correlation of location to attitude change, as the Melbourne data revealed that the highest

Table 6. Characteristics of sample and breakdown of attitude change per group

\begin{tabular}{|c|c|c|c|}
\hline \multirow[b]{2}{*}{ Demographics } & & \multirow{2}{*}{$\begin{array}{c}\% \text { of changed } \\
\text { attitudes towards } \\
\text { homelessness } \\
(\text { Melbourne }) \\
(\text { Overall }=52.2 \%)\end{array}$} & \multirow{2}{*}{ 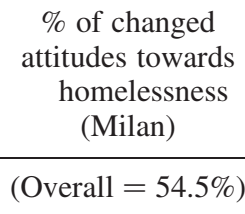 } \\
\hline & & & \\
\hline Gender & $\begin{array}{l}\text { Female } \\
\text { Male }\end{array}$ & $\begin{array}{l}54.4 \% \\
50.3 \%\end{array}$ & $\begin{array}{l}59.3 \% \\
51.7 \%\end{array}$ \\
\hline Age & $\begin{array}{l}18-25 \text { years } \\
25-29 \text { years } \\
30-34 \text { years } \\
35-50 \text { years } \\
50+\text { years }\end{array}$ & $\begin{array}{l}59.0 \% \\
51.6 \% \\
54.2 \% \\
38.5 \% \\
54.8 \%\end{array}$ & $\begin{array}{l}63.9 \% \\
57.9 \% \\
60.0 \% \\
46.7 \% \\
47.6 \%\end{array}$ \\
\hline Location & $\begin{array}{l}\text { Host city } \\
\text { Interstate } \\
\text { Overseas }\end{array}$ & $\begin{array}{l}51.1 \% \\
61.1 \% \\
53.8 \%\end{array}$ & $\begin{array}{l}56.9 \% \\
18.8 \% \\
68.1 \%\end{array}$ \\
\hline Attendance & & & \\
\hline Number of days & $\begin{array}{l}\text { One } \\
\text { Two } \\
\text { Three } \\
\text { More than four }\end{array}$ & $\begin{array}{l}46.8 \% \\
48.6 \% \\
58.7 \% \\
70.0 \%\end{array}$ & $\begin{array}{l}48.0 \% \\
55.8 \% \\
66.7 \% \\
90.0 \%\end{array}$ \\
\hline $\begin{array}{l}\text { Hours spent daily } \\
\text { at event }\end{array}$ & $\begin{array}{l}\text { One } \\
\text { Two to three } \\
\text { Four to five } \\
\text { More than five }\end{array}$ & $\begin{array}{l}46.4 \% \\
50.3 \% \\
54.5 \% \\
75.0 \%\end{array}$ & $\begin{array}{l}39.5 \% \\
47.8 \% \\
64.1 \% \\
70.0 \%\end{array}$ \\
\hline $\begin{array}{l}\text { Planned or incidental } \\
\text { attendance }\end{array}$ & $\begin{array}{l}\text { Passing through the area } \\
\text { Intentionally attending event }\end{array}$ & $\begin{array}{l}48.3 \% \\
52.4 \%\end{array}$ & $\begin{array}{l}47.0 \% \\
62.2 \%\end{array}$ \\
\hline
\end{tabular}


proportion of attitude change took place for interstate attendees, whereas the Milan data revealed that overseas visitors reported the highest proportion of attitude change.

The final research stage examined the characteristics of people who had undergone different attitudinal changes towards the issue of homelessness as a result of event attendance. Cross tabulations were used to investigate where attitude changes could be aligned to the attitudinal and behavioural characteristics tested.

Although greater-sized samples and further development of measures around the three specific attitude changes are required to expand on the use of a self-reported measure, we identify notable findings in assessing the forms of attitude changes. Males were higher on changes in awareness while females were much more likely to alter attitudes in an empathetic manner. The age group 25-29 revealed the highest rates of enhanced opinions. Residents from the host city scored high on enhanced opinions and empathy, while visitors were higher on awareness. Those intentionally attending the event underwent more of an empathetic change while those who attended incidentally (i.e., were just passing by) were more likely to change in awareness towards the issue. Those attending with family were high on enhanced opinions and low on awareness. Higher attendance was equated with higher rates of empathy, while lower attendance resulted in higher rates of enhanced opinions.

The findings presented above in Tables 5 and 6 identify that the nature of attitude change towards the issue of homelessness by HWC spectators is linked to spectator attendance patterns (i.e., how many days and hours attending the event), the gender of the spectators and the home location of the spectator. These attendance and demographic factors appear to play a role in the type of attitude change undertaken, which in turn impacts the likely result of attending the event or altering behaviours related to the social cause. Increased scrutiny of the demographic analysis of spectator attendance patterns may provide opportunities for future research.

It is also relevant to note that each major city hosting a sport event will consist of more than one community. Although the concept of fostering social capital within a diverse community of spectators, including those originating from outside the host city, may be considered problematic, it can be argued that diversity and heterogeneity are to be expected, and the bridging and linking between these diverse groups is an example of social capital at play.

\section{Discussion}

Using data collected from multiple editions of the HWC, attitudes towards the community benefits of the event and attitudes to the social issue of homelessness were measured. While no differences are seen across data collected from the two events, we show that the level of perceived event benefits are dependent on demographic characteristics such as gender and origin of the spectator as well as patterns of attendance at the event. Further, we show significant correlations exist between event benefits and various attitudes towards homelessness. The analysis of the open-ended responses provides some understanding of the findings of the quantitative data by seeking to identify the specific types of attitudinal change observed, and additionally to identify whether correlations between demographics and attitudinal change existed.

Quantitative analysis revealed that females and respondents from the host country were more likely to have higher measures of the perception of community events and homelessness attitudes, and that higher rates of attendance equated to higher positive changes in attitudes. These findings are unsurprising as the relevance of local events to 
local people is self evident, and attendees that spend more time at an event have either a willingness to do so as a result of their existing empathy, or possibly as a result of increased exposure to the message at an event. No significant differences across the two sample populations were observed, which is indicative of the cross-cultural application of the findings across developed countries.

Coding of open responses supported these notions and, through self-reported attitude change and analysis of the nature of this attitude change, these findings were extended to show three categories of attitude change towards the social issue. We find some trends that suggest demographic and attendance patterns also play a role in these attitude changes.

The data revealed the following trends: males showed greater changes in awareness, while females had a greater propensity for empathetic change; younger age brackets (e.g. 25-29) had greater levels of enhanced opinion of the participants; spectators' originating from the host country had higher levels of empathy and enhanced opinion, whilst visitors scored higher on awareness; and the greater the attendance, the more empathetic change occurred. Intentional attendance also scored higher on empathetic change, while unintentional attendance showed higher levels of changes in awareness.

Attitudinal change in spectators may be best understood in terms of a hierarchy of effects model. Hierarchy of effects (HOE) have been developed in the marketing field to describe the stages that people sequentially experience while forming or developing attitudes and intentions. Smith, Chen and Yang note the existence of multiple versions of HOE models, yet state that these consistently identify a set of systematic responses that are able to be identified as a sequential process. ${ }^{24}$ This research provides a first attempt to understand how an event may change the perceptions of the attending spectators in regards to a social issue, using the concept of hierarchy of effects by identifying the sequential processing of spectators' attitudes.

Three types of attitudinal change were identified in the self-reported changes of the respondents. In consideration of this, a hierarchy of effects from awareness to states of enhanced opinion and empathetic change is worthy of discussion. As evidenced, incidental attendance led to higher awareness and planned attendance led to higher empathy. Additionally, higher attendance correlated with higher levels of empathy. This suggests that attitude changes of HWC spectators may be constructed to 'reveal a systematic response process that can be divided into sequential stages for closer examination'. ${ }^{25}$

This paper provides an argument that events such as the HWC can affect attitudinal change in spectators towards the event, but also towards social issues, in this case, homelessness. The results of this research supports the notion that the accrual of social capital is able to be attained by attendance at an event and invites further investigation into the possibility of the role of HOE in stages of attitudinal change.

Chalip argues that the 'feel good' nature of sport events can 'sustain agendas for social and community action'. ${ }^{26}$ It is the aim of an event such as the HWC to facilitate such a change, specifically an attitudinal change in the host community, and indeed the global community, regarding the issues of homelessness and social exclusion. This aim is most clearly stated within the HWC mission statement:

We will realise this mission using a combination of a global football tournament and local football initiatives. The first, organised as a world-class event, will gain impact, reputation and media interest, which will encourage funding and promotion of innovative grass-root concepts on a local level. ${ }^{27}$

Spectator attitudes demonstrate opportunities created to engender bridging capital in the community, as a change in attitude by each spectator impacts on the broader 
community attitude towards homelessness and marginalization. Support for this event from the community in terms of positive community attitudes is a demonstration of the value being placed on the building of social capital to validate the execution of such events.

In addition to attitudinal change, the HWC - and particularly the grass-roots street soccer program - provides substantive event outcomes for the host community, event participants and volunteers. The HWC interacts with global and local communities to develop education and awareness campaigns, and also to facilitate the creation of local and international films and documentaries, to continue to promote the message and mission of the HWC. Additionally, the global movement of social media, with Facebook pages and Twitter accounts established on behalf of the HWC, provides the ability for continued involvement within a virtual community. This development of community links between disparate individuals across the globe, possessing a common social cause, is an additional example of engendering social capital.

\section{Conclusion}

Although based on exploratory work through spectator surveys and observations at two HWC events, this paper argues that spectator attitudinal change can facilitate the behavioural outcomes which lead to the development of social capital, and deliver social benefits to the event host community. This has implications for the Homeless World Cup Organisation in achieving its stated goal of awareness-raising for homelessness and poverty internationally. Understanding the conditions by which attitudinal change takes place will assist in guiding event managers in planning and designing events and also implementing the promotion of the social message at the event and for extended legacy programmes and activities. Such research that seeks to classify and evaluate attitudinal change also justifies the facilitation and support of sport events as platforms for attitudinal changes on a societal level.

Sport events are increasingly being linked to social outcomes, or to support a particular social issue. The aim of many sport events with a social cause is to create community benefit, where spectators who experience attitudinal change towards a social issue develop a more positive or empathic understanding. The findings and resulting attitude change of spectators, and specifically those who experienced empathy with the HWC participants, supports the view that events can facilitate the building of social capital. By creating increased understanding between different social groups, greater community cohesion and more inclusive social capital may be developed.

In summary, $52.2 \%$ of attendees at the Melbourne HWC and $54.5 \%$ of attendees at the Milan HWC indicated that this event had changed their attitudes towards homelessness. Coding of open responses categorized these changes in three areas: awareness, enhanced opinions and empathy. Cross tabulation revealed the propensity of those undergoing attitudinal change, and that the nature of the change differed across patterns of attendance as well as gender and the location of the attendee.

The findings show that social attitudes are not invariantly facilitated in spectators and that changes can be more pronounced given demographic and attendance profiles. Identifying the impact that personal characteristics and attendance patterns have on this outcome presents clear practical implications for event organizers in the design and implementation of event planning. Strength of attitude was seen to be related to depth of attendance (both in numbers of days and hours per day attended) suggesting attempts to maximize patronage length and repeat attendance at an event increases the likely impact 
and opportunity for attitude change. Trends in the data suggest gender and location of attendees also promote differences in the level of attitude change. Future research might further explore the link between satisfaction with the event experience and the resultant attitudinal change.

As a self-reported, exploratory measure, it can be argued that events such as the HWC have been successful at changing attitudes towards particular social issues. While it would be ideal to measure attitudes to these areas before and after the event, we find that there are various distinct forms of attitudinal change which have taken place at this single point in time. This suggests that further research would be useful by surveying spectators before they attend the event and again shortly after they have attended the event to identify if this attitudinal change to the social issue is enduring, implicating the relevance of a longitudinal research design. Additionally, developing scales to specifically measure each of the three types of attitudinal change (awareness, enhanced opinion, empathy) would confirm the presence and drivers (i.e., gender, attendance) of different forms of change.

This study appears to reflect a similar hierarchy of effects to that found in other disciplines, however in the case of an event with a social cause, the positive intent or behavioural outcome is not a purchase but a change in attitude towards the social cause which may in turn represent an increased likelihood to support that cause, through donation or other action (for example, volunteering). While this was beyond the scope of the current paper, the development of social-cause attitudes from awareness, to positively changing perceptions, to a positive intent or behaviour presents a logical framework for future research. While untested, it may be realistically posited, in line with suggestions of how sponsorship is said to work, that positive or empathetic responses may result in more positive outcomes or behavioural activity than pure awareness towards a product or service, or in this case, a social issue.

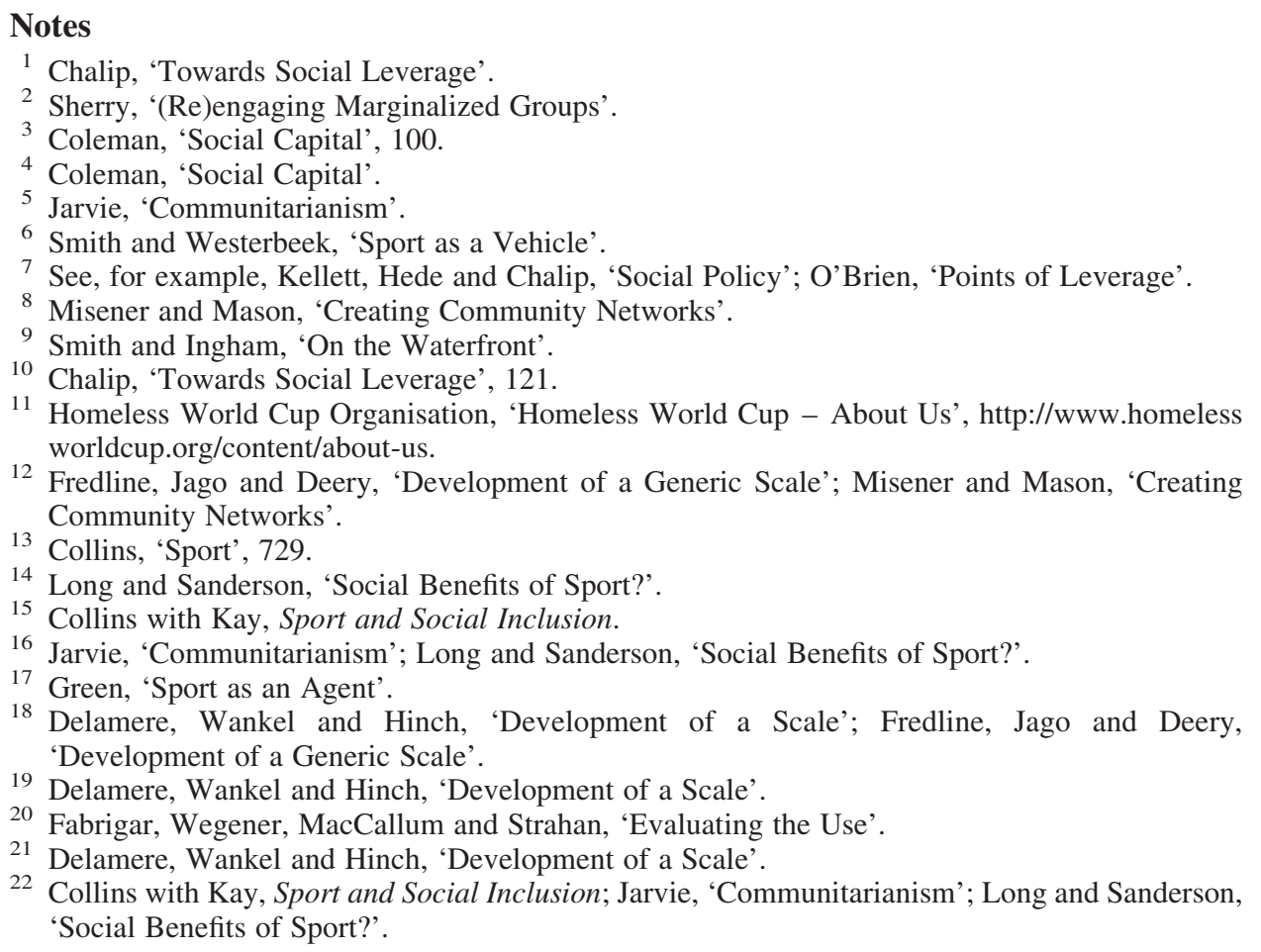


${ }^{23}$ See, for example, Strauss and Corbin, Basics of Qualitative Research.

${ }^{24}$ Smith, Chen and Yang, 'Impact of Advertising', 50.

25 Ibid.

26 Chalip, 'Towards Social Leverage', 122.

${ }^{27}$ Homeless World Cup Organisation, 'Homeless World Cup - About Us - Mission', http://www. homelessworldcup.org/content/about-us.

\section{References}

Chalip, Laurence. 'Towards Social Leverage of Sport Events'. Journal of Sport and Tourism 11, no. 2 (2006): 109-27.

Coleman, James S. 'Social Capital in the Creation of Human Capital'. American Journal of Sociology 94, S1 (1998): S95-120.

Collins, Mike. 'Sport, Physical Activity and Social Exclusion'. Journal of Sports Sciences 22, no. 8 (2004): 727-40.

Collins, Mike, with Tess Kay. Sport and Social Inclusion. London: Routledge, 2003.

Delamere, Thomas A., Leonard M. Wankel, and Thomas D. Hinch. 'Development of a Scale to Measure Resident Attitudes Toward the Social Impacts of Community Festivals, part I: Item Generation and Purification of the Measure'. Event Management 7, no. 1 (2001): 11-24.

Fabrigar, Leandre R., Duane T. Wegener, Robert C. MacCallum, and Erin J. Strahan. 'Evaluating the Use of Exploratory Factor Analysis in Psychological Research'. Psychological Methods 4, no. 3 (1999): 272-99.

Fredline, Liz, Leo Jago, and Margaret Deery. 'The Development of a Generic Scale to Measure the Social Impacts of Events'. Event Management 8, no. 1 (2003): 23-37.

Green, B. Christine. 'Sport as an Agent for Social and Personal Change'. In Management of Sports Development, edited by Vassil Girginov, 130-45. London: Butterworth-Heinemann, 2008.

Jarvie, Grant. 'Communitarianism, Sport and Social Capital'. International Review for the Sociology of Sport 38, no. 2 (2003): 139-53.

Kellett, Pamm, Anne-Marie Hede, and Laurence Chalip. 'Social Policy for Sport Events: Leveraging (Relationships with) Teams from other Nations for Community Benefit'. European Sport Management Quarterly 8, no. 2 (2008): 101-21.

Long, Jonathon, and Ian Sanderson. 'The Social Benefits of Sport? Where's the Proof?'. In Sport in the City: The Role of Sport in Economic and Social Regeneration, edited by Chris Gratton and Ian P. Henry, 187-203. London: Routledge, 2001.

Misener, Laura, and Daniel Mason. 'Creating Community Networks: Can Sporting Events Offer Meaningful Sources of Social Capital?'. Managing Leisure 11 (2006): 39-56.

O’Brien, Danny. 'Points of Leverage: Maximizing Host Community Benefit from a Regional Surfing Festival'. European Sport Management Quarterly 7, no. 2 (2007): 141-65.

Sherry, Emma. '(Re)engaging Marginalized Groups Through Sport: The Homeless World Cup'. International Review for the Sociology of Sport 45, no. 1 (2010): 59-71.

Smith, Aaron C.T., and Hans Westerbeek. 'Sport as a Vehicle for Deploying Social Corporate Responsibility'. Journal of Corporate Citizenship 7, no. 25 (2007): 43-54.

Smith, Jason M., and Alan G. Ingham. 'On the Waterfront: Retrospectives on the Relationship Between Sport and Communities'. Sociology of Sport Journal 20, no. 3 (2003): 252-74.

Smith, Robert E., Jiemiao Chen, and Xiaojing Yang. 'The Impact of Advertising Creativity on the Hierarchy of Effects'. Journal of Advertising 37, no. 4 (2008): 47-62.

Strauss, Anselm, and Juliet Corbin. Basics of Qualitative Research. Thousand Oaks, California: Sage Publications, 1998. 
Appendix 1. EFA results for Community Benefits Scale (Melbourne sample)

Items $(\mathrm{n}=358)$

Community benefits

The HWC helps to show others why my community is unique and special .817

The HWC is a celebration of my community

Hosting the HWC improves the quality of life for my community $\quad .758$

The HWC contributes to a sense of community well-being $\quad .758$

$\begin{array}{ll}\text { The HWC contributes to my personal well-being } & .749\end{array}$

The HWC gives us an opportunity to show other people how special our 631 community is

Eigenvalue

Average Variance Explained (AVE)

Appendix 2. Correlation analysis of community benefits and homelessness attitudes

\begin{tabular}{lcccccc}
\hline & $\mathrm{H} 1$ & $\mathrm{H} 2$ & $\mathrm{H} 3$ & $\mathrm{H} 4$ & $\mathrm{H} 5$ & $\begin{array}{c}\text { Community } \\
\text { benefits }\end{array}$ \\
\hline $\begin{array}{l}\text { H1 - The issue of homelessness } \\
\text { is something I worry about }\end{array}$ & 1 & & & & & \\
$\begin{array}{l}\text { H2 - I feel that I can help } \\
\text { make a positive } \\
\text { change to homelessness in } \\
\text { (host country) }\end{array}$ & $.400 * *$ & 1 & & & \\
$\begin{array}{l}\text { H3 - There are too } \\
\text { many homeless people }\end{array}$ & $.414 * *$ & $.313 * *$ & 1 & & \\
$\begin{array}{l}\text { in (host country) } \\
\text { H4 - I support the government's } \\
\text { focus on the homeless issue }\end{array}$ & $.197 * *$ & $.182 * *$ & $.208 * *$ & 1 & \\
$\begin{array}{l}\text { H5 - There should be no } \\
\text { homelessness in a country }\end{array}$ & $.315 * *$ & $.195 * *$ & $.361 * *$ & $.245 * *$ & 1 & \\
$\begin{array}{l}\text { like (host country) } \\
\text { Community benefits }\end{array}$ & $.301 * *$ & $.426 * *$ & $.254 * *$ & $.200 * *$ & $.325 * *$ & 1 \\
\hline
\end{tabular}

N.B. Combined samples used given no significant differences were found between samples (Table 2).

$* *$ Significance $=\mathrm{p}<.05$ 